03

\title{
Интенсификация парообразования и вторичного измельчения капель огнетушащих составов
}

\author{
() Д.В. Антонов, П.А. Стрижак \\ Национальный исследовательский Томский политехнический университет, Томск, Россия \\ E-mail: pavelspa@tpu.ru
}

Поступило в Редакцию 5 августа 2019г.

В окончательной редакции 5 августа 2019г.

Принято к публикации 31 октября 2019г.

\begin{abstract}
Представлены результаты экспериментальных исследований парообразования и фрагментации капель огнетушащих составов на примере суспензий и эмульсий. Показано (на примере рапсового масла), что при добавлении в их состав горючей жидкости растительного происхождения можно реализовать микровзрывной распад и частичную фрагментацию, которые являются режимами вторичного измельчения капель. Установлены диапазоны изменения времен существования капель при разных температурах нагрева и концентрации компонентов.
\end{abstract}

Ключевые слова: вторичное измельчение, капли огнетушащих жидкостей, нормализованная площадь, микровзрывное разрушение.

DOI: 10.21883/PJTF.2020.03.48987.18008

Экспериментальные исследования, натурные и полевые испытания последних лет показали, что современные технологии тушения и локализации пожаров позволяют эффективно использовать не более $20-30 \%$ от объема жидкости [1]. Под эффективным применением принято понимать полное испарение жидкости в зоне горения [2], так как интенсификация эндотермических фазовых превращений с высокой теплотой парообразования (около $2 \mathrm{MJ} / \mathrm{kg}$ в случае воды и составов на ее основе) позволяет реализовать три основных механизма подавления горения [3]: снижение температуры; замещение разогретых газов водяными парами; блокирование смешения окислителя, продуктов пиролиза и горения. К сожалению, даже в условиях авиационного тушения крупных городских и лесных пожаров доля испарившейся жидкости из сброшенного объема невысока [4], несмотря на применение разнообразных добавок. На их основе готовятся суспензии бентонита, растворы бишофита и ОС-5, эмульсии пенообразователей и др. Известный подход к интенсификации испарения жидкостей в зоне горения состоит в их тонкодисперсном распылении $[5,6]$, но его реализация, как правило, затруднена в связи с высокой вязкостью огнетушащих составов и уносом из зоны горения мелких капель продуктами сгорания [7]. Одно из перспективных решений задачи направленной доставки требуемого объема жидкости в зону горения и ее измельчения состоит в микровзрывной фрагментации, т. е. разрушении крупных капель с образованием мелкодисперсного аэрозоля [8-10]. Но пока в полной мере установлены необходимые условия микровзрывной фрагментации лишь капель водосодержащих топлив [8-10]. Основной механизм этих процессов состоит в перегреве негорючего компонента - воды до температуры кипения, что приводит к зарождению пузырьков пара, их росту, наполнению капли парами и ее разрушению. До сих пор не предпринимались попытки микровзрывного измельчения капель огнетушащих составов за счет добавления жидкого горючего компонента к воде или другой жидкости, так как такое смешение может приводить даже к интенсификации горения. Необходим поиск безопасной горючей добавки к тушащей жидкости с минимальной концентрацией, достаточной для микровзрывной фрагментации капель в зоне горения. В [10] показано, что интенсивное микровзрывное измельчение в высокотемпературной газовой среде капель воды возможно при добавлении в их состав даже 3 vol.\% рапсового масла. Эта жидкость растительного происхождения относится к числу трудновоспламеняемых и безопасных для лесных массивов. Поэтому рациональным представляется определение характеристик микровзрывного измельчения капель огнетушащих составов в высокотемпературной среде за счет добавления рапсового масла. В этом и состоит цель настоящей работы.

С помощью высокоскоростной видеокамеры Phantom Miro M310 выполнялась регистрация процессов фрагментации капель при конвективном нагреве вследствие обдувания потоком разогретого воздуха. Схема стенда аналогична используемой в опытах [10]. Поток формировался с применением нагревателя (Leister LHS 61, максимальная температура воздуха на выходе $700^{\circ} \mathrm{C}$ ) и нагнетателя (Leister Robust, расход воздуха до 12001/min) [10]. Диапазон исследуемых температур составил $300-500^{\circ} \mathrm{C}$, скорость движения натекающего на каплю газового потока около $3 \mathrm{~m} / \mathrm{s}$. При этих температурах и скоростях движения потока капля не срывалась с держателя (полой металлической трубки с внутренним и внешним диаметрами 0.3 и $0.5 \mathrm{~mm})$, 


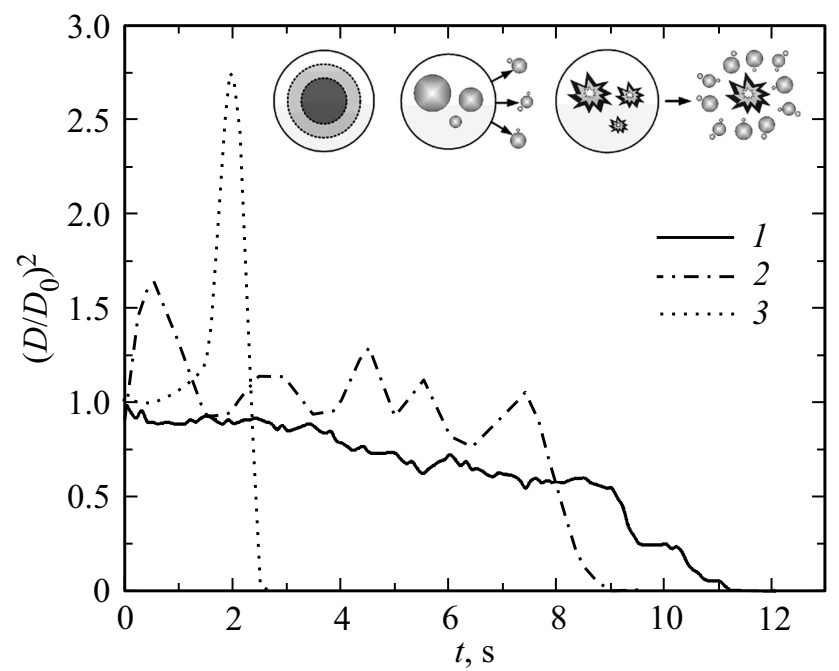

Pис. 1. Типичные тренды изменения во времени нормализованной площади поверхности капель (начальный диаметр $D_{0} \approx 2.67 \mathrm{~mm}$ ) перспективных огнетушащих жидкостных составов при температуре нагрева $500^{\circ} \mathrm{C} .1$ - испарение с сохранением целостной структуры капли, 2 - частичная фрагментация, 3 - микровзрывное измельчение.

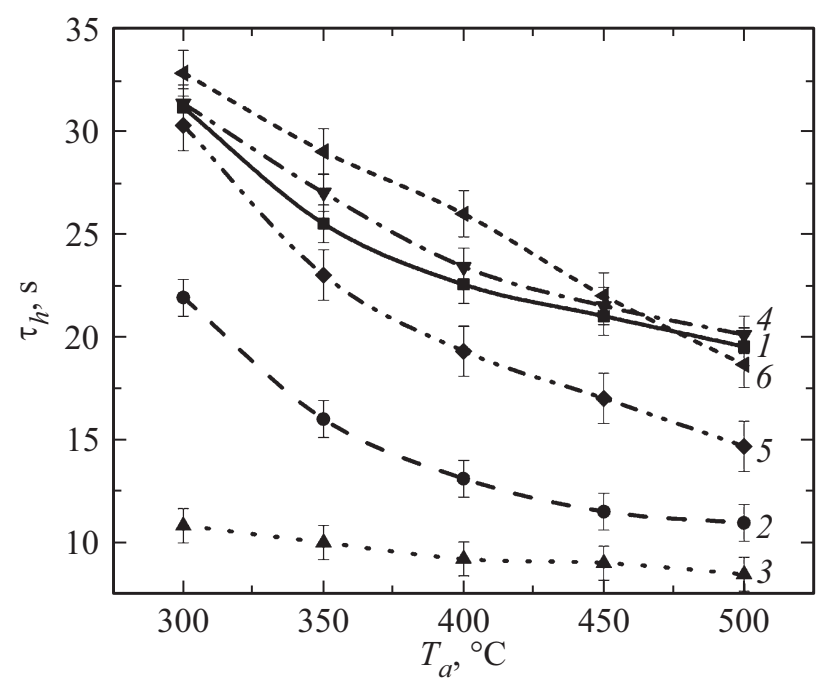

Рис. 2. Зависимости от температуры нагрева времен существования (в режимах монотонного испарения, частичной фрагментации или микровзрывного разрушения) капель (начальный диаметр $D_{0} \approx 2.67 \mathrm{~mm}$ ) огнетушащих жидкостей. 1 суспензия бентонита $(10 \mathrm{wt} . \%), 2$ - суспензия бентонита (10wt.\%), рапсовое масло (3vol.\%); 3 - суспензия бентонита (10wt.\%), рапсовое масло $(10$ vol.\%), 4 - смесь суспензии бентонита (5wt.\%) и эмульсии пенообразователя (5vol.\%), 5 - дистиллированная вода, 6 - эмульсия пенообразователя $(10 \mathrm{vol} . \%)$.

и устойчиво реализовалась фрагментация огнетушащих составов за счет добавления рапсового масла. В экспериментах использовались наиболее перспективные по своим свойствам для тушения пожаров составы (суспензия бентонита, эмульсия пенообразователя), а также составы с добавлением рапсового масла. Концентрация последнего варьировалась в диапазоне 3-10 vol.\%. Аналогично методике [10] для генерации капель использовались электронные дозаторы Finnpipette Novus (шаг варьирования генерируемого объема $0.05 \mu 1)$.

Обработка видеозаписей осуществлялась в два этапа. На первом выполнялось слежение за изменением нормализованной площади $\left(D / D_{0}\right)^{2}$ испаряющейся капли во времени. С использованием программных алгоритмов слежения Airbag и Advanced Airbag проводился контроль изменения формы капли. Погрешности определения $\left(D / D_{0}\right)^{2}$ не превышали $5 \%$. На втором этапе анализировались времена существования $\tau_{h}$ (в режимах монотонного испарения, частичной фрагментации или микровзрывного разрушения) капель огнетушащих составов в зависимости от температуры. Погрешность определения $\tau_{h}$ не превышала $3 \%$.

На рис. 1 представлены типичные зависимости от времени нормализованной площади поверхности капель (начальный диаметр $D_{0} \approx 2.67 \mathrm{~mm}$ ) огнетушащих жидкостных составов при температуре нагрева $500^{\circ} \mathrm{C}$. Выделены три основных режима существования капель перспективных огнетушащих жидкостных составов: монотонное испарение, частичная фрагментация и микровзрывное полное разрушение. Для первого режима характерно практически монотонное уменьшение нормализованной площади во времени, а для второго (частичной фрагментации) - периодические колебания нормализованной площади во времени вследствие отрыва фрагментов. Регистрировались последовательные этапы увеличения размеров капель (рис. 1) за счет формирования пузырей и отрыва вторичных капель с уменьшением суммарного объема капли. Третий режим характеризовался значительным начальным увеличением капли в объеме, а затем разрывом родительской капли с образованием облака мелких фрагментов вторичных капель радиусами менее $0.01 \mathrm{~mm}$ [10]. Условные схемы для каждого режима представлены на рис. 1.

На рис. 2 показаны зависимости от температуры нагрева времен существования (в режимах монотонного испарения, частичной фрагментации и полного микровзрывного разрушения) капель (начальный диаметр $D_{0} \approx 2.67 \mathrm{~mm}$ ) огнетушащих жидкостей. Наибольшие времена существования соответствуют огнетушащим составам без добавления рапсового масла. Добавление последнего в состав капель позволило значительно (в 2-3 раза) снизить времена существования. При концентрации растительного компонента менее 3 vol.\% реализовалось монотонное испарение огнетушащих составов, при концентрации от 3 до 10 vol.\% - частичная фрагментация (режим „puffing ${ }^{6}$ ), при концентрации выше 10 vol.\% - микровзрывное измельчение. Средние времена существования капель исследованных жидкостей от максимальных к минимальным значениям при добавлении растительного компонента составили $19.53 \mathrm{~s}$ (без добавления рапсового масла), $10.95 \mathrm{~s}$ (3 vol.\% рапсового 
масла) и 8.45 s (10 vol.\% рапсового масла). При регистрации процессов испарения, диспергирования и распада огнетушащих составов установлено, что для составов с пенообразователем характерна флуктуация поверхности капли за счет интенсивного формирования пузырей, а суспензиям бентонита свойственно вытягивание капли (переход от сферической формы к эллипсоидальной) на держателе за счет агломерирования частиц, скапливающихся в ее нижней части.

Различия времен существования капель на рис. 2 обусловлены не только деформацией и фрагментацией капель, но и сменой доминирующих механизмов нагрева. С учетом результатов опытов $[7,10]$ можно было предположить, что при добавлении твердых частиц в состав капель воды будет ускоряться прогрев последних за счет трех механизмов: больше энергии излучения поглощается вследствие повышенного значения степени черноты частиц; интенсифицируется термогравитационная конвекция в капле; уменьшается теплоемкость и увеличивается теплопроводность (соответственно растет температуропроводность). Но из рис. 2 видно, что времена испарения суспензий больше, чем для воды без примесей. Температуропроводность частиц бентонита выше аналогичного параметра для воды в 4-5 раз [7], но вследствие их неравномерного распределения в составе капель и агломерирования прогрев последних был неравномерным. На заключительном этапе существования капель данные частицы скапливались и затрудняли выход влаги из области между ними. Поэтому замедлялся процесс уменьшения размера капли на видеограммах. Регистрировалось налипание данных частиц на поверхность держателя. В реальной практике при движении капель и их вращательной деформации твердые частицы будут непрерывно перемешиваться. Поэтому можно прогнозировать ускорение прогрева относительно времен на рис. 2.

Для составов с пенообразователем установлены достаточно большие длительности испарения капель (рис. 2). Это обусловлено тем, что при смешении пенообразователя с водой формируется капля, наполненная многочисленными мелкими газовыми пузырьками. Это приводит к тому, что уменьшается эффективная (средняя с учетом долей компонентов) теплопроводность капли (значения этого параметра для воздуха и паров на порядок ниже, чем для воды). Поэтому на видеограммах было хорошо видно, что капля довольно медленно уменьшалась в размерах в процессе прогрева. Добавление пенообразователя даже с малой относительной концентрацией в любой из исследованных составов приводило к росту времен полного испарения вследствие указанных причин, но также способствовало фрагментации исходной капли при высоких температурах нагрева вследствие наполнения пузырьками паров. Это связано с тем, что для пенообразователя характерно в $1.5-2$ раза меньшее поверхностное натяжение по сравнению с водой. Поэтому пенообразователь в условиях высоких температур можно использовать для интенсификации распада капель.
Наиболее перспективным представляется высокотемпературный нагрев многокомпонентной капли, которая содержит воду, горючий компонент, твердые частицы и пенообразователь. Можно за счет выбора температуры регулировать режим и скорости парообразования.

В целом на рис. 2 видно нелинейное снижение времен существования капель при увеличении температуры. Оно обусловлено главным образом экспоненциальными зависимостями скоростей испарения горючих и негорючих жидких компонентов от температуры [7-10]. Чем значительнее изменения этих скоростей при росте температуры, а также чем меньше температуры кипения и воспламенения компонентов, тем существеннее менялись времена существования капель $\tau_{h}$.

Таким образом, проведенные эксперименты показали, что все перспективные огнетушащие жидкостные составы можно дополнительно измельчать (средний размер капель можно уменьшить в 3-7 раз) за счет добавления малой доли рапсового масла (менее 10 vol.\%). При этом возможна реализация трех режимов парообразования капель в высокотемпературной области: монотонное испарение; частичная фрагментация; полное взрывное измельчение. В зависимости от требуемой площади контакта горящей конструкции и огнетушащей жидкости можно реализовать один из этих трех режимов.

\section{Финансирование работы}

Исследование выполнено при поддержке гранта Президента РФ (МД-314.2019.8).

\section{Конфликт интересов}

Авторы заявляют, что у них нет конфликта интересов.

\section{Список литературы}

[1] Zhdanova A.O., Volkov R.S., Voytkov I.S., Osipov K.Yu., Kuznetsov G.V. // Int. J. Heat Mass Transfer. 2018. V. 126. P. 703-714.

[2] Voitkov I.S., Volkov R.S., Zhdanova A.O., Kuznetsov G.V., Nakoryakov V.E. // J. Appl. Mech. Tech. Phys. 2018. V. 59. P. 891-902.

[3] Korobeinichev O.P., Shmakov A.G., Shvartsberg V.M., Chernov A.A., Yakimov S.A., Koutsenogii K.P., Makarov V.I. // Fire Safety. J. 2012. V. 51. P. 102-109.

[4] Kopylov N.P., Kuznetsov A.E., Kuznetsov G.V., Sushkina E.Yu., Karpov V.N. // Fire Safety. 2018. V. 6. P. 377-389.

[5] Коробейничев О.П., Шмаков А.Г., Чернов А.А., Большова Т.А., Швариберг В.М., Куценогий К.П., Макаров В.И. // Физика горения и взрыва. 2010. Т. 46. № 1. С. 20-25.

[6] Алеханов Ю.В., Близнецов М.В., Власов Ю.А., Дудин В.И., Левушов А.Е., Логвинов А.И., Ломтев С.А., Мешков Е.Е. // Письма в ЖТФ. 2003. Т. 29. В. 6. С. 1-6.

[7] Voytkov I.S., Volkov R.S., Lutoshkina O.S., Kuznetsov G.V. // Exp. Therm. Fluid Sci. 2018. V. 98. P. 20-29. 
[8] Tarlet D., Mura E., Josset C., Bellettre J., Allouis C., Massoli P. // Int. J. Heat Mass Transfer. 2014. V. 77. P. 1043 1054.

[9] Sazhin S.S., Rybdylova O., Crua C., Heikal M., Ismael M.A., Nissar Z., Aziz A.R.B.A. // Int. J. Heat Mass Transfer. 2019. V. 131. P. $815-821$.

[10] Антонов Д.В., Кузнецов Г.В., Стрижсак П.А. // Письма в ЖТФ. 2019. Т. 45. В. 16. С. $14-17$. 